\title{
PERSATUAN DAN KESATUAN
}

Noviana Neni Honggu

lik Strada Indonesia

nnyhonggu@gmail.com

\begin{abstract}
ABSTRAK
Persatuan dan kesatuan berasal dari kata satu yang memiliki arti utuh atau tidak terpecah belah.

Kandungan arti persatuan dan kesatuan adalah bersatunya macammacam corak yang beraneka ragam menjadi satu kebulatan yang utuh dan serasi.

Sebuah negara akan menjadi kokoh jika masyarakatnya memiliki semnagat persatuan dan kesatuan.

Prinsip persatuan dan kesatuan adalah keadaan satu atau tunggal yang menuntut adanya keterpaduan dari kemajemukan bangsa indonesia.

Persatuan indonesia merupakan sila ketiga dalam pancasila. Sesuai sila tersebut ,bangsa indonesia adalah bangsa multikultular yang terdapat banyak kebudayaan,suku dan ras. Semua perbedaan itu bisa bergabung menggunakan persatuan.

Sebagai generasi penerus bangsa, sangat penting berkomitmen terhadap semnagat persatuan dalam konteks NKRI, yang berdasarkan Pancasila dan UUD 1945 dan bersemboyan Bhineka Tunggal Ika.
\end{abstract}

\section{Latar Belakang}

Persatuan dan Kesatuan adalah bersatunya macam-macam corak yang beraneka ragam menjadi satu kebulatan yang utuh dan serasi.

Negara Indonesia sebagai negara kesatuan yang memiliki keragaman suku, agama, dan ras, serta wilayah yang sangat luas terdiri dari ribuan pulau yang berdiri pada pertengahan abad ke-20 atau persis melalui proklamasi kemerdekaan, tanggal 17 Agustus 1945 yang bernaung di dalam Negara Kesatuan Republik Indonesia (NKRI). Konsep neggara kesatuan lahir dari adanya 
pemikiran negara kesatuan mengenai keinginan warga masyarakat suatu negara dalam upaya untuk membentuk suatu kesatuan yang kokoh.

Proklamasi kemerdekaan pada tanggal 17 Agustus 1945 telah mengakhiri rentetan penderitaan bangsa indonesia sebagai bangsa yang terjajah.Proklamasi telah melahirkan Indonesia sebagai negara baru yang mempunyai kedudukan sejajar dengan bangsa lainnya yang telah merdeka terlebih dahulu.

Proklamasi kemerdekaan tidak akan pernah terjadi apabila tidak adanya persatuan dan kesatuan di antara warga negara indonesia. Persatuan dan kesatuan bangsa harus selalu kita jaga, supaya Negara Kesatuan Republik Indonesia tetap menunjukkan eksistensinya dan menjadi negara mandiri yang terbebas dari berbagai intervensi atau campur tangan asing.

\section{Kasus/masalah}

Polisi rangkus 8 pelaku Tawuran Antarpelajar di wilayah Kembangan jakarta barat, akibatnya 1 korban luka bacok di kepala,punggung dan kaki

\section{Poskota.co.id}

Tawuran terjadi pada senin (4/10) lalu sekiar pukul 14:30 WIB saat jam pulang sekolah.

Kanit Reskrim Polsek Kembangan AKP Ferdo Elfiyanto menjelaskan awalnya polisi menerima laporan adanya seorang pelajar yang terluka dan berada di puskesmas.

"TKP-nya ini di jalan Kembang Utara deket patung sapu itu pecahnya tawuran.Kondisi korban mengalami luka di kepala, di punggung, juga di kaki," ujarnya di Polsek Kembangan, Senin (25/10/2021).

Dari delapan pelaku yang di amankan, mereka memiliki peran yang berbeda. Pelaku utama RS alias A (18) berperan sebagai orang yang melakukan pembacokan kepala korban.

"kalau di lihat korban ada luka di kepala, itu luka akibat pelaku ini," ucap Ferdo.

Pelaku selanjutnya berinisial $\mathrm{RS}$ alias $\mathrm{J}$ dan $\mathrm{RD}$ alias $\mathrm{P}$ mereka berdua menyediakan senjata tajam untuk RS dan MFR.

Pelaku lainnya berinsial HA dan MDA ketahuan memiliki senjata tajam tanpa izin.

Begitupun dengan kedua pelaku MR (18) dan MJS (19) juga ketahuan memiliki senjata tajam. 
Ferdo mengatakan jika tawuran tersebut bermula dari ajakan di media sosial.

Kedua kelompok pelajar tersebut melakukan tawuran di karenakan ada gengsi satu sama lain.

"Ini pembelajaran bagi kita mengingat PPKM level 2 sekolah mulai tatap muka, maka kepolisian khususnya Kembangan berpesan ke orang tua dan sekolah untuk mengawasi para pelajar dan anak didik agar terhindar dari tawuran. Sehingga tidak ada korban jiwa," paparnya.

Daari tangan para pelaku polisi menyita enam buah sajam berjenis celurit dan enam unit sepeda motor .

Atas perbuatan kedelapan pelaku tersebut, polisi menerapkan pasal yang berbeda-beda. Ini di karenakan kategori kejahatan yang mereka perbuat tidak sama.

Pelaku berinisial RS alias A, MFR alias $\mathrm{O}, \mathrm{RS}$ alias $\mathrm{J}$ dan RD alias $P$ di kenakan pasal 170 KUHP tentang pengeroyokan dan terancan maksimal hukuman 10 tahun penjara. Sedangkan HA, MDA,MR dan MJS di kenakan UU Darurat Pasal 2 di karenakan memiliki senjata tak berizin dan terancam maksimal hukuman 10 tahun penjara.

\section{Tinjauan Pustaka}

Pengertian Persatuan dan Kesatuan menurut Syarbaini (2010:43) Menyatakan bahwa "Persatuan mengandung arti bersatunya macam-macam corak yang beraneka ragam menjadi satu kebulatan yang utuh dan serasi".

Menurut WJS.Poerwadaminta,(2003;30) Kesatuan adalah bentuk kesatuah adalah bentuk ke-esaan, sifat tunggal atau bentuk keseutuhan.

Menurut Kamus Besar Bahasa Indonesia Persatuan adalah suatu gabungan (ikatan dan kumpulan) dengan bagian yang sudah utuh bersatu,perserikatan dan serikat.

Sementara untuk pengertian kesatuan berarti suatu perihal satu,keesaan,sifat yang tunggal, dan kesatuan.

Faktor yang mempengaruhi tidak adanya Persatuan dan Kesatuan

- Menurut www.bola.com

- Keberagaman masyarakat indonesia 
Adanya keberagaman yang dimiliki rakyat indonesia dapat menjadi penghaambat persatuan dan kesatuan bangsa. Terutama apabila tidak di iringi dengan sikap saling menghargai, menghormati, serta adanya toleransi yang telah menjadi karakter khas masyarakat indonesia.

Keberagaman tersebut dapat mengakibatkan munculnya perbedaan pendapat yang memicu lepas kendali, tumbuhnyaperasaan kedaerahan yang berlebihan, yang dapat memicu terjadinya konflik antardaerah atau antarsuku bangsa.

- Ketidakpuasan terhadap ketimpangan ekonomi Kondisi ekonomi yang timpang bisa memperlemah persatuan dan kesatuan bangsa. Jadi, apabila ketimpangan dan ketidakmerataan pembangunan serta hasil-hasil pembangunan masih belum dapat diatasi, bisa menimbulkan ketidakpuasan hingga perpecahan.

Ketidakpuasan tersebut biasanya akan menimbulkan pertentangan antara pemerintah daerah dan pemerintah pusat.

- Melemahnya nilai budaya bangsa Nilai-nilai budaya bangsa dapat melemah akibat kuatnya pengaruh budaya asing yang tidak sesuai dengan kepribadian bangsa, baik melalui kontak maupun kontak tidak langsung.

Kontak langsung antara lain melalui unsur-unsur pariwisata. Kontak tidak langsung, antara lain melalui media elektronik televisi,radio,film,internet,telepon seluer yang mempunyai fitur stsu fasilitas yang lengkap.

- Menurut www.kompas.com

- Perpecahan bangsa Jika rakyat Indonesia tidak memikiki persatuan dan kesatuan, maka tidak akan terwujud kemerdekaan yang di proklamasikan pada 17 Agustus 1945.

Salah satu dampak tidak adanya persatuan dan kesatuan adalahn perpecahan bangsa. 
Karena setiap individu kelompok merasa memiliki kepentingan sendiri dan tidak memperdulikan kepentingan orang lain. Jika tidak di antisipasi, tidak heran bangsa menjadi pecah.

- Melemahnya pertahanan dan keamanan Tidak adanya persatuan dan kesatuan dalam kehidupan berbangsa dan bernegara juga akan berdampak pada melemahnya pertahanan dan keamanan bangsa. Ketika rakyat tidak lagi bersatu malah bertikai sendiri, maka serangan dari luar akam mudah masuk. Mereka tidak hanya masuk, tetapi juga akan mempengaruhi rakyat.

- Terjadi konflik antar kelompok

Konflik antar kelompok akan terjadi ketika setiap individu atau kelompok tidak memiliki sikap persatuan dan kesatuan.

- Menurut www.detik.com

- Keluarga

Keluarga adalah institusi pertama dalam kehidupan sosial. Oleh karena itu keharmonisan dalam sebuah keluarga adalah hal yang sangat penting.

Dalam setiap keluarga diperlukan adanya sikap saling menghormati satu sama lain agar terjadinya persatuan dan kesatuan dalam keluarga semakin kuat. Dampak jika tidak ada persatuan dan kesatuan dalam keluarga adalah sebagai berikut:

$\checkmark$ Terjadinya pertengkaran di dalam keluarga

$\checkmark$ Kerukunan di dalam keluarga akan berkurang

$\checkmark$ Keakraban di dalam keluarga juga akan berkurang.

- Sekolah

Persatuan dan kesatuan juga di perlukan dalam sekolah. Hal itu di karenakan agar tercipta lingkungan yang harmonis saat kegiatan belajar dan mengajar. Berikut adalah dampak jika tidak ada persatuan dan kesatuan tidak terwujud di sekolah: 
$\checkmark$ Sombong serta acuh atau tidak peduli terhadap kondisi teman.

$\checkmark$ Membeda-bedakan teman.

$\checkmark$ Mengolok-olok teman.

$\checkmark$ Terjadi tawuran.

- Masyarakat

Persatuan dan kesatuan dalam kehidupan bermasyarakat sangatlah penting. Jika memiliki perbedaan pendapat dalam kehidupan bermasyarakat sangatlah normal dan tidak akan terjadi kekacauan jika memiliki persatuan dan kesatuan.

Dampak yang terjadi akibat tidak adanya persatuan dan kesatuan dalam masyarakat:

$\checkmark$ Tidak adanya kepedulian teerhadap penderitaan dan kesedihan yang dialami dan di rasakan orang lain.

$\checkmark$ Kepentimgan golongan maupun suku masing-masing adalah yang paling dipentingkan oleh masyarakat.

$\checkmark$ Kepentingan golongan maupun sukku masing-masing adalah yang paling dipentingkan oleh masyarakat.

$\checkmark$ Tidak adanya kerja sama yang terjalin antar warga masyarakat, padahal gotong royong sangat di prioritaskan dalam kehidupan bermasyarakat.

\section{Pembahasan}

Pengertian persatuan dan kesatuan

Persatuan adalah gabungan (ikatan,kumupulan dan sebagaunya) beberapa bagian yang sudah bersatu, perserikatan, serikat. Sementara itu pengertisn kesatuan berarti perihal satu, keesaan,sifat tunggal,satuan.

Dampak persatuan dan kesatuan bagi diri kita sendiri

$\checkmark$ Bisa mengatasi perbedaan dengan penuh kesadaran.

$\checkmark$ Pembangunan nasional akan berjalan lebih lancar,aman dan baik.

$\checkmark$ Bangsa indonesia lebih mudah untuk maju

> Damapak persatuan dan kesatuan bagi orang lain 
$\checkmark$ Tidak adanya toleransi

$\checkmark$ Perpecahan masyarakat dan bangsa

$\checkmark$ Melemahnya pertahanan dan keamanan negara

5. Kesimpulan

Kita harus bersatu tanpa memandang status atau golongan. Untuk membangun persatuan kita harus ada kesatuan saling sepakat agar tercapai segala tujuan dan keinginan bersama.

Oleh karena itu kita sebagi masyarakat indonesia harus menanamkan sikap Gotong royong, tolong menolong,otonomi daerah,sifat kekeluargaan,musyawarah dalam pengambilan keputusan,kerja sama antar umut beragama yang berbeda, tidak membeda-bedakan suku,agama,dan ras.

\section{Daftar Pustaka}

https://www.tribunnews.com

https://www.kompas.com

http://respository.upi.edu

https://scholar.google.co.id/citations?view op=view citation\&hl=id \&user=I7XCpelAAAAJ\&citation for view=17XCpelAAAAJ:MXK kJ rixJIC 